\title{
NONOPERATIVE MANAGEMENT OF NEGLECTED CLUBFOOT- OUR EXPERIENCE
}

\author{
P. Anil Babu1, G. Vara Prasad ${ }^{2}$
}

${ }^{1}$ Assistant Professor, Department of Orthopaedics, Guntur Medical College, Guntur, Andhra Pradesh. ${ }^{2}$ Professor, Department of Orthopaedics, Government General Hospital, Guntur.

ABSTRACT

\section{BACKGROUND}

The incidence of congenital talipes equinovarus is approximately one in every 1000 live births. Most cases are sporadic in occurrence. Contractures or anomalies of the soft tissues exert further deforming forces and resist correction of bony deformity and realignment of the joints. Our study has been done to know the efficacy of nonoperative management.

\section{MATERIALS AND METHODS}

Our study is done with children presenting with neglected clubfoot at different ages from one year to two years of age. The deformity in these children is persisting because of no treatment or discontinued treatment after early initial attempts for correction.

\section{RESULTS}

The target set for achieving Pirani is 0 with clinical deformity turning to neutral or overcorrection. The Pirani score improvement achieved in 10 out of 42 cases.

\section{CONCLUSION}

Nonoperative management even in neglected cases of clubfoot can be tried to correct the deformity while preserving the normal anatomy in favourable progressions.

\section{KEYWORDS}

Neglected Clubfoot, Nonoperative Management, Deformity Correction.

HOW TO CITE THIS ARTICLE: Babu PA, Prasad GV. Nonoperative management of neglected clubfoot- Our experience. J. Evolution Med. Dent. Sci. 2017;6(40):3168-3171, DOI: 10.14260/Jemds/2017/684

\section{BACKGROUND}

The congenital talipes equinovarus (Clubfoot) occurs with an incidence of 1 in every 1000 live births. These are sporadic in occurrence. Various theories proposed regarding the cause of clubfoot do not clearly indicate why the severity is seen in some cases. Primary germ plasm defect theory attributes this to defect in Talus causing continued plantar flexion and inversion, leading to soft-tissue changes in the joints and musculotendinous complexes. Theory of primary soft-tissue abnormalities attribute the deformity to abnormalities in neuromuscular units which in turn cause secondary bony changes. Children with clubfoot present with hypotrophic anterior tibial artery along with atrophy of the musculature in the calf. Abnormal distribution of type I and type II muscle fibres in clubfeet is well documented. The size of abnormal foot may be one half to one size smaller in length and width.

To treat the clubfoot the pathological changes of anomaly should be considered from planning itself. The clubfoot deformity complex comprises equinus, varus, and adduction deformities. The foot with deformity presents a variety of severities for the given deformity. The equinus may involve entire foot with varus deformity of forefoot, adducted and cavus deformities.

Financial or Other, Competing Interest: None.

Submission 12-04-2017, Peer Review 07-05-2017,

Acceptance 12-05-2017, Published 18-05-2017.

Corresponding Author:

Dr. P. Anil Babu,

\#5-54-120, 101 Suryodaya Residency,

$6 / 18$, Brodipet,

Guntur-522002

Andhra Pradesh.

E-mail: anilpbabu@gmail.com

DOI: $10.14260 /$ jemds $/ 2017 / 684$
Clubfoot is accompanied by internal tibial torsion. All the joints in the mid and hind foot can be involved in the pathological process.

The correction can be resisted by contractures or soft tissue anomalies which in turn act as deforming forces, resisting reduction and maintenance of reduction. Forces that can influence talocalcaneal joint are calcaneofibular ligament, the superior peroneal retinaculum (calcaneal fibular retinaculum), the peroneal tendon sheaths, and the posterior talocalcaneal ligament. Forces that can influence talonavicular joint are posterior tibial, the deltoid ligament, the calcaneonavicular ligament, the whole talonavicular capsule, the dorsal talonavicular ligament, the bifurcated ( $\mathrm{Y}$ ) ligament, the inferior extensor retinaculum, and occasionally the cubonavicular oblique ligament.

The metatarsals may show deviation at the tarsometatarsal joints, or these joints may be normal, and metatarsals assume adducted position.

In cases of persisting or recurring clubfoot, adaptive changes occur at the bony level resulting in irreducibility with manipulations. These changes are very much dependent on the severity of the soft-tissue contractures and the period for which the patient has walked.

The severity of the deformity that can be graded by Classifications by Pirani et al and Diméglio et al are based solely on physical examination and require no radiographic measurements or other special studies. Pirani system is composed of 10 different physical examination findings (Fig. 1), each scored 0 for no abnormality, 0.5 for moderate abnormality, or 1 for severe abnormality. Each foot is assigned a total score, the maximum being 10 points, with a higher score indicating a more severe deformity.

In the system of Diméglio et al, four parameters are assessed on the basis of their reducibility with gentle 
manipulation as measured with a handheld goniometer(1): equinus deviation in the sagittal plane,(2) varus deviation in the frontal plane,(3) derotation of the calcaneopedal block in the horizontal plane,(4) and adduction of the forefoot relative to the hind foot in the horizontal plane.

Initially the clubfeet are treated nonoperatively. Various treatment regimens have been proposed, including the use of corrective splinting, taping, and casting. Treatment consists of weekly serial manipulation and casting during the first 6 weeks of life, followed by manipulation and casting every other week until the foot is clinically and radiographically corrected. The more rigid the initial deformity, the more likely that surgical treatment will be required.

On the higher side, successful correction of clubfoot deformity generally is reported in $90 \%$ to $98 \%$ of children treated with Ponseti casting. Achilles tenotomy or anterior tibial tendon transfer is added to the casting routine when necessary.

The Ponseti method consists of two phases: treatment and maintenance. The treatment phase should begin as early as possible, optimally within the first week of life. Gentle manipulation and casting are done weekly.

Maintenance Phase: when the final cast is removed, the infant is placed in a brace that maintains the foot in its corrected position (abducted and dorsiflexed). The brace (foot abduction orthosis) consists of shoes mounted to a bar in a position of 70 degrees of external rotation and 15 degrees of dorsiflexion. The distance between the shoes is set at about 1 inch wider than the width of the infant's shoulders. This brace is worn 23 hours each day for the first 3 months after casting and then while sleeping for 2 to 3 years.

Management of Recurrence: Recurrence of the deformity usually will not occur when the bracing is properly followed. Long leg casts with 2-week intervals can effectively correct early recurrence. The neglected variety should be differentiated from recurrent clubfoot. The children who were treated earlier with early intervention, with manipulations, serial casting or surgery can have a recurrence due to growth spurt. Relapses, in these cases can occur as a result of incomplete initial correction or inadequate compliance to bracing. In all relapsed clubfeet, a large degree of initial correction is achieved and subsequent deformity tends not to be as severe as in neglected clubfeet. Usually, the child is still walking on the sole of the foot and is able to wear shoes, although deforming them out of shape. There may be associated iatrogenic deformities. ${ }^{[3]}$ The neglected clubfoot never received initial treatment or may have received very inadequate and incomplete initial treatment.

Out of all the deformities, forefoot adduction remains a difficulty from using previous correction methods. ${ }^{[4]}$ The initial management of CTEV by Ponseti method has many advantages.

Untreated CTEV and its recurrence will result in long-term disability and deformity. For this intervention can be conservative such as splinting or stretching or surgical.

Parent counselling is of utmost importance before and during the course of deformity correction. Any deviation in the regular followup can lead to delay in correction and even recurrence. This poses a newer issue, because of weightbearing at around ten months of age on an uncorrected foot, before achieving a plantigrade foot, will lead to bony deformity, creating incongruous surfaces at the joints.
Neglected CTEV or clubfoot is still seen among rural populations, where parent counselling has not been done or owing to the poor socioeconomic status regular visits are made to a speciality centre. For any reason forcing the child to miss serial manipulations and casting, the deformity gets exaggerated and more difficult to treat. In this scenario, the cases of neglected clubfoot are presenting with deformity in a child who has already started walking.

Due to weightbearing on uncorrected foot the weight is borne by non-keratinised lateral aspect of the midfoot leading to formation of callosities, as well as cracks on them. The child cannot wear normal footwear. The foot never experiences proper weightbearing, and it is impossible to wear normal shoes.

\section{MATERIALS AND METHODS}

Our study is done with children presenting with clubfoot at different ages from one year to two years of age. The deformity in these children is because of negligence, where no treatment was attempted or discontinued before correction is achieved.

Our study is to know the efficacy of nonoperative management.

The inclusion criterion for the study were: a) children of one to two years of age, b) no attempt is made to correct the deformity, c) previous history of discontinued treatment before correction.

The exclusion criterion were: a) deformity with other congenital conditions, b) doubtful infections at the callosity.

The study has included 42 children with the above said deformity with age distribution and severity scores as given in the tables.

\begin{tabular}{|c|c|}
\hline Age & Children \\
\hline 12 months & 16 \\
\hline $13-15$ months & 9 \\
\hline $16-18$ months & 12 \\
\hline $19-24$ months & 5 \\
\hline Table 1. Age Distribution in 42 Cases \\
\hline
\end{tabular}

\begin{tabular}{|c|c|}
\hline Pirani Score & Children \\
\hline 6 & 18 \\
\hline 7 & 4 \\
\hline 8 & 17 \\
\hline 9 & 3 \\
\hline \multicolumn{2}{|c|}{ Table 2. Severity Distribution in 42 Cases } \\
\hline
\end{tabular}

The children were evaluated for malnourishment, anaemia and skin infections. 31 children were found to be anaemic and with borderline PEM. The parents were counselled about the general condition and about different treatment options for neglected clubfoot.

All the children in the study group are treated with Ponseti manipulations and POP Castings. The manipulation is done with forefoot and midfoot manipulation to correct supination, adduction and varus. The degree of deformity is clinically evaluated and to what extent the manipulation can be done is decided by the initial comfort of the child and nail bed blanching. Each above-knee POP casting is maintained for two weeks and further manipulation is attempted. The manipulations and serial castings are continued for three times and observed for any improvement of severity and Pirani scores. The children showing minimum improvement of 1 in Pirani scores are further continued to undergo POP 
castings. For the children who are not showing improvement in Pirani scores, the manipulations are discontinued. The time spent in the POP castings for all the children is utilised to improve the general condition.

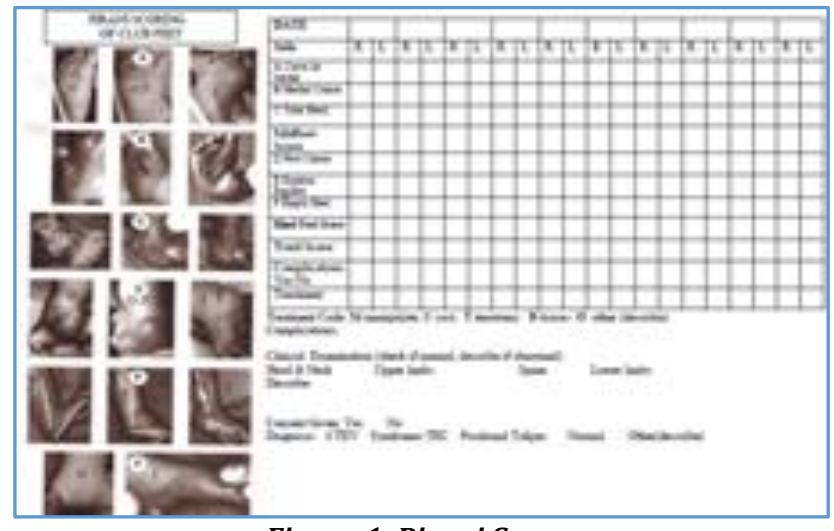

Figure 1. Pirani Scores
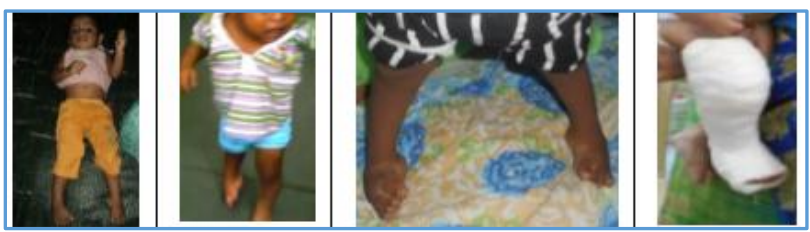

Figure 2. Neglected Clubfoot

\section{RESULTS}

The results of our study are based on the improvement in the Pirani Scores. The evaluation was done once in every two weeks. The improvement has been very slow as 38 children did not show any improvement during the first manipulation. This can be attributed to the period of weightbearing till the first manipulation done.

Ten children have shown progress from the first manipulation and the same is consistently shown till five manipulations spread across ten weeks. The final scores achieved in these children are Pirani score 0 . These children were again maintained with strict adherence to bracing with DB Splints. Further followup of these children at monthly interval for one year has shown no recurrence and plantigrade foot is maintained.

In the children where no improvement of Pirani scores is seen, the manipulations are discontinued and patients are prepared for surgical management.

\begin{tabular}{|c|c|c|c|c|c|c|c|c|}
\hline 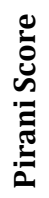 & 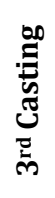 & 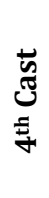 & 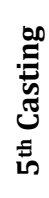 & 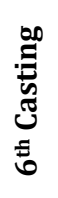 & 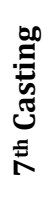 & 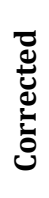 & 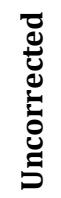 & 坖 \\
\hline 6 & 4 & 3 & 2 & 1 & 0 & 7 & 11 & 18 \\
\hline 7 & 5 & 5 & 3 & 2 & 0 & 3 & 1 & 4 \\
\hline 8 & 8 & 8 & \multicolumn{3}{|c|}{ Discontinued } & 0 & 17 & 17 \\
\hline 9 & 9 & 9 & \multicolumn{3}{|c|}{ Discontinued } & 0 & 3 & 3 \\
\hline \multicolumn{9}{|c|}{ Rate of Progression as per Pirani Score } \\
\hline
\end{tabular}

For the more resistant group with no improvement in scores, it has become evident from third casting and it is discontinued after fourth casting and the children are advised to undergo surgical options.

One serious complication noticed in the study was development of pressure sores in children not showing improvement of Pirani scores. No improvement and pressure sores are the reasons for discontinuation of treatment.

\section{DISCUSSION}

CTEV is one of the commonest congenital deformities. It is a complex deformity comprising of equinus, varus, adductus and cavus. It requires meticulous and dedicated effort on the part of treating physician and parents for the correction of the deformity. The goal of treatment is to reduce or eliminate these deformities so that patient has a functional, pain free, plantigrade foot with good mobility without calluses and does not need to wear modified shoes.(5) Unfortunately, even in present times children are not brought to medical facilities where early detection and treatment can be offered.

The Ponseti casting technique of correction of CTEV deformity requires serial corrective casts with long term brace maintenance of the correction. The treatment needs to be started as soon as possible and should be followed under close supervision.(6) The Ponseti casting technique yielded satisfactory anatomical and functional result, being simple, effective, minimally invasive, inexpensive and ideally suited for all countries and cultures.

The available literature suggests that the results were better if this method of treatment was started as early as possible after birth. The factors responsible for clubfoot deformity are active from the $12^{\text {th }}$ to $20^{\text {th }}$ weeks of foetal life up to 3-5 years of age. One of them reported that the Ponseti technique significantly improved foot alignment compared to the Kite technique. After 10 weeks of serial casting, the average total Pirani score of the Ponseti group was 1.15 (95\% confidence interval 0.98 to 1.32), lower than that of the Kite group.(7) There is enough evidence to suggest that Ponseti method can be tried for manipulations compared to other methods. Surgical correction of the neglected, and severely deformed clubfoot in the adult is necessary to achieve plantigrade, pain free, and cosmetically acceptable feet. Also, it is important that the patient is able to wear shoes and participate in a more active and normal life.(8) The entire onus cannot be assigned to surgical methods, because whatever correction that can be achieved by manipulations can have less time spent on surgical methods to get the correction of the deformity.

\section{CONCLUSION}

We would like to conclude that (a) parent counselling and early management of Clubfoot is essential to prevent a much severe, even sometimes a rigid deformity; (b) nonoperative management of neglected clubfoot can be started with serial manipulations and castings irrespective of severity with safety measures; (c) the general condition of the child should always be improved to discontinue the treatment and to proceed with operative management; (d) neglected clubfoot requires operative management in majority of cases.

\section{REFERENCES}

[1] Lohia LK, Meena S, Kanojia RK. Comparative study of complete subtalar release and Joshi's external stabilization system in the management of neglected and resistant idiopathic clubfoot. Foot Ankle Surg 2015;21(1):16-21.

[2] Singh A. Evaluation of neglected idiopathic CTEV managed by ligamentotaxis using jess: a long-term followup. Adv Orthop 2011;2011:6. 


\section{Jemds.com}

[3] Penny JN. The neglected clubfoot. Techniques in Orthopaedics 2005;20(2):153-66.

[4] Chen W, Pu F, Yang Y, et al. Correcting congenital talipes equinovarus in children using three different corrective methods: a consort study. Medicine (Baltimore) 2015;94(28):e1004.

[5] Ullah SM, Noor-Ul FK, Shahjahan M, et al. Management of congenital talipes equino varus (CTEV) by Ponseti casting technique in neonates: our experience. J Neonatal Surg 2013;2(2):17.

\section{Original Research Article}

[6] Duffy CM, Salazar JJ, Humphreys L, et al. Surgical versus Ponseti approach for the management of CTEV: a comparative study. J Pediatr Orthop 2013;33(3):32632.

[7] Gray K, Pacey V, Gibbons P, et al. Interventions for congenital talipes equinovarus (clubfoot). Cochrane Database Syst Rev 2012;4:CD008602.

[8] Sobel E, Giorgini R, Velez Z. Surgical correction of adult neglected clubfoot: three case histories. J Foot Ankle Surg 1996;35(1):27-38. 